\title{
Preparation and structure characterization of soluble bone collagen peptide chelating calcium
}

\author{
Yong-Guo Jin, Wen-Wen Fu, and Mei-Hu Ma* \\ College of Food Science and Technology, Huazhong Agricultural University, Wuhan 430-070, China.
}

Accepted13 April, 2011

\begin{abstract}
In this study, G-25 gel chromatography, X-diffraction, scanning electron microscopy (SEM), UV and Fourier transform infrared spectroscopy (FTIR) were used to analyze soluble collagen peptides chelating calcium. Collagen peptide hydrolysis can be divided into four components using G-25 gel chromatography. Each component of calcium binding capacity was different and the components whose molecular weight was less than $5000 \mathrm{Da}$ had a relatively high calcium binding capacity. In the infrared spectra experimental certification, after the collagen peptides had combined with calcium, amide I, II wave number was displaced, which indicated that amino nitrogen atoms and oxygen atoms on the carboxyl groups were involved in chelation. In the UV scan spectra, the characteristic absorption peak of the collagen peptide's carbonyl and the peptide bond was clearly shifted, indicating that collagen peptides have reacted with calcium. In SEM spectra, a lot of white grains were seen to be "embedded" clearly in the surface of the collagen peptide, indicating that besides the reaction of coordination between collagen peptides and calcium, there was a certain degree of adsorption. After combination with calcium, the X-ray diffraction spectra showed that the no rules non-crystal structure collagen peptides turned into rules crystal structure. According to the structure analysis which showed that collagen peptide chelated calcium is a five-membered ring structure, calcium is in the center and was combined strongly with both the amino- and carboxyl-group.
\end{abstract}

Key words: Bone, calcium binding, molecular weight, collagen peptide.

\section{INTRODUCTION}

Calcium is essential for living organisms. It is the main construct of skeletal organizations, which can support the entire body structure and all kinds of physiological and biological processes in the body. Also, it could play an important role in intracellular metabolism, bone growth, blood clotting, nerve conduction, muscle contraction and cardiac functions (Anderson and Garner, 1996; Bass and Chan, 2006). The body must maintain its blood level of calcium, because if calcium is not adequately absorbed into the bloodstream from food or supplements, it is moved from the skeleton, and will then result to a series of problems. However, calcium can be quite difficult to absorb. There are some concerns that inadequate

"Corresponding author. E-mail: mameihuhn@yahoo.com.cn. Tel: +86-27-8728-3177. Fax: 86-27-8728-3177. calcium is absorbed because of the precipitation of insoluble calcium salts in the neutral to slightly basic intestinal lumen and also the loss of calcium. Recently, there has been a great deal of interest in the beneficial effects of food ingredients (particularly protein) on calcium dissolution and subsequent calcium absorption (Lonnerdal et al., 1989; Miyazawa and Yoshida, 1991; Saito et al., 1998). For example, numerous previous studies reported that casein phosphopeptides (CPP) have been found to dissolve calcium in the intestine and thus promote calcium absorption in growing rats (Lee et al., 1980; Saito et al., 1998). Jung and Kim (2007) isolated the highest affinity peptides (Val - Leu - Ser Gly - Gly - Thr - Thr - Met - Tyr - Ala - Ser - Leu - Tyr Ala - Glu) to calcium, and also found that this oligopeptide and calcium binding capacity was considerable to casein phosphopeptides. Bao et al. (2008) found the molecular weight (14.4 KDa and 8 to 9 
$\mathrm{KDa}$ ) of soybean protein hydrolyzate peptide with calcium ion binding capacity as the strongest, and the calcium binding capacity of peptides in linear correlation with the carboxyl group content. However, there were few researchers that worked on the mechanism and degree of calcium ion binding until now.

Accordingly, the collagen which was extracted from bovine bone combined with calcium is able to produce new substances through enzymolysis. The obtained hydrolysates can provide normal daily intake of amino acids needed, and the necessary calcium for the body. In this study, the differences in soluble complexes formed by combination of protein hydrolysates with calcium were investigated in an attempt to determine the calciumpeptide binding mechanism.

\section{MATERIALS AND METHODS}

Ox bone (19\% crude protein content) was purchased from a local market in Huazhong University of Agriculture, whereas papain, neutrase and alkaline protease were purchased from Guangxi Nanning Pangbo Biotechnology Company and Trypsin BioTechnology Co., Ltd., Shanghai Kai Yang. Acid protease was obtained from Wuhan Jie Yang Sheng Bio-Technology Co., Ltd., while Sephadex G-25 was purchased from Amersham Pharmacia Biotech, Sweden. However, all chemicals were of analytical grade.

\section{Preparation of collagen protein hydrolysates}

Bone ash $(2.0 \mathrm{~g})$ was dissolved in $100 \mathrm{ml}$ of distilled water. After adjustment of the $\mathrm{pH}, 5000 \mathrm{u} / \mathrm{g}$ protease was added into the protein solution. Enzymatic hydrolysis was performed at $\mathrm{pH} 3.0$ and $50^{\circ} \mathrm{C}$ for acid protease, $\mathrm{pH} 5.5$ and $50^{\circ} \mathrm{C}$ for papain, $\mathrm{pH} 7.0$ and $50^{\circ} \mathrm{C}$ for neutrase, $\mathrm{pH} 8.5$ and $50^{\circ} \mathrm{C}$ for alkaline protease, and $\mathrm{pH} 8.0$ and $55^{\circ} \mathrm{C}$ for trypsin. After digestion for $3 \mathrm{~h}$, the solutions were heated in boiling water for $10 \mathrm{~min}$ to inactivate the proteases and cooled to room temperature. The $\mathrm{pH}$ was adjusted to 7.4 and the mixtures were centrifuged at $4000 \times \mathrm{g}$ for $20 \mathrm{~min}$. The supernatants were lyophilized and labeled as hydrolysates $A C, P, N, A L$ or T depending on the protease employed in the digestion.

\section{Extraction of soluble calcium from bone residue}

According to the preliminary tests, $2 \mathrm{~mol} / \mathrm{L}$ of hydrochloric acid were used for the reaction. The bone residue was extracted with hydrochloric acid according to the volume of the reaction (1:20) $(\mathrm{g} / \mathrm{ml})$. After digestion for $1 \mathrm{~h}$, the solutions were cooled to room temperature and the insoluble fraction was filtered, while the supernatant was transferred to a neutral $\mathrm{pH}$ using calcium hydroxide.

\section{Preparation of collagen peptide chelating calcium}

$20 \mathrm{mg}$ portion of the lyophilized hydrolysates was dissolved in distillated water, followed by $10 \mathrm{~min}$ incubation at $50^{\circ} \mathrm{C}$ to ensure full dissolution. After adding $1 \mathrm{ml}$ of $0.04 \mathrm{~mol} / \mathrm{L} \mathrm{CaCl} 2$ solutions, the $\mathrm{pH}$ was maintained at 7.8 with a $\mathrm{pH}$ meter, and the solution was incubated for $30 \mathrm{~min}$. The solid pellet was discarded and the supernatant was transferred to a dialysis bag (MWCO100, Sorua, Germany) to remove free $\mathrm{Ca}^{2+}$ and other low molecular weight compounds. Changes in calcium concentration were monitored using EDTA titration (Purkinje General Instruments, Beijing, China). The concentration of chelated $\mathrm{Ca}^{2+}\left[\left(\mathrm{Ca}^{2+}\right)\right.$ bind)] was calculated by the following equation:

$\left[\mathrm{Ca}^{2+}\right]$ bind $=\left[\mathrm{Ca}^{2+}\right]$ total $-\left[\mathrm{Ca}^{2+}\right]$ free

Where, $\left[\mathrm{Ca}^{2+}\right]$ total is the total concentration of $\mathrm{Ca}^{2+}$.

\section{Sephadex G-25 gel chromatography}

Samples of the lyophilized hydrolysates were dissolved in distillated water and fractionated by size exclusion chromatography using a Sephadex G-25 $(1.0 \times 80 \mathrm{~cm})$ column equilibrated and eluted with the distillated water. Fractions of $1 \mathrm{ml}$ were collected at a flow rate of 8 drops per minute, absorbed at $280 \mathrm{~nm}$. Potassium dichromate (294.18 Da), Thyme Finland (466Da), Vitamin B12 (5.73 kDa) and bovine serum albumin $(65 \mathrm{kDa})$ were used as molecular weight standards. A standard curve was generated by plotting the logarithm of molecular weights $(\lg \mathrm{M})$ against $\mathrm{Ka}$, and the average molecular weight of each sample was determined using the standard curve.

\section{Infrared spectrometer}

Free water or crystal water of the samples were removed, and then $2 \mathrm{mg}$ of the solid samples was taken into the Ma Agate mortar, which was added into the dry spectrum of pure $\mathrm{KBr} 200 \mathrm{mg}$. It was uniformly grinded (in the infrared lamp) into tablet molds, to a particle size below $2.5 \mu \mathrm{m}$. The pressure, which was about $60 \mathrm{MPa}$, was exhausted and maintained for 3 - $5 \mathrm{~min}$. Consequently, a relief of the pressure resulted to transparent $\mathrm{KBr}$ sample films, and the Shimadzu IR-435 Infrared spectrophotometer was used for the qualitative analysis of the spectrum.

\section{UV scanning analysis}

The UV-Vis spectrophotometer was opened and preheated for 20 min. Some of the samples were dissolved in distilled water and centrifuged at $4000 \times g$ for $10 \mathrm{~min}$. The distilled waters reference solution was taken and scanned between 190 and $400 \mathrm{~nm}$.

\section{X-diffraction analysis}

The sample was uniformly grinded to a particle size below $10 \mu \mathrm{m}$, and the sample powder was filled into the sample area. Pressure with the glass-to-earth requires the sample surface to be flushed with the glass surface. For the sample test, the diffractometer total power was opened and the circulating pump was started. After a few minutes later, the computer was opened and the X-ray diffraction applications were applied, while the tube voltage, tube current to the required value and the appropriate diffraction conditions and parameters were set.

\section{Statistical analysis}

The sample treatments described in this study were conducted in triplicate, and all analyses were performed in duplicate, with values reported as means $\pm S D$. Analysis of variance (ANOVA) was used to determine the significance of differences in the data, while values of $p<0.05$ were considered to be statistically significant. However, statistical analysis was performed using the Origin Pro 7.5 software package (OriginLab Corp., Mass., U.S.A.). 


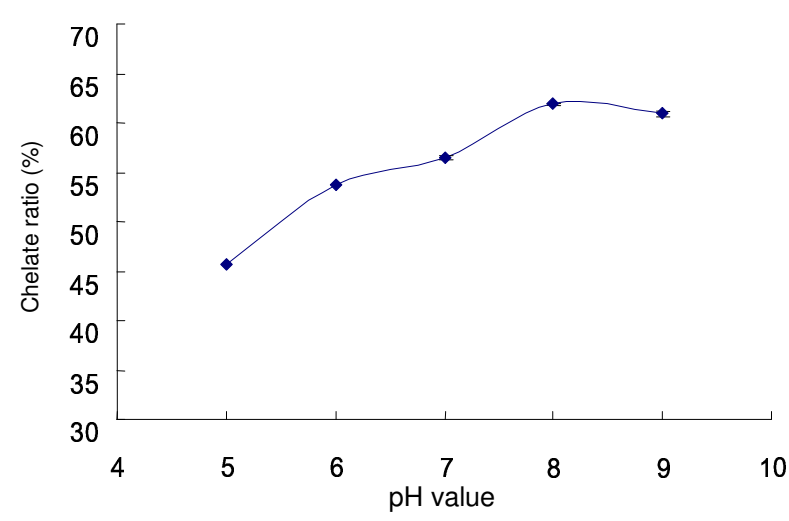

Figure 1. The effect of $\mathrm{pH}$ value on the chelate ration of the chelate reaction.

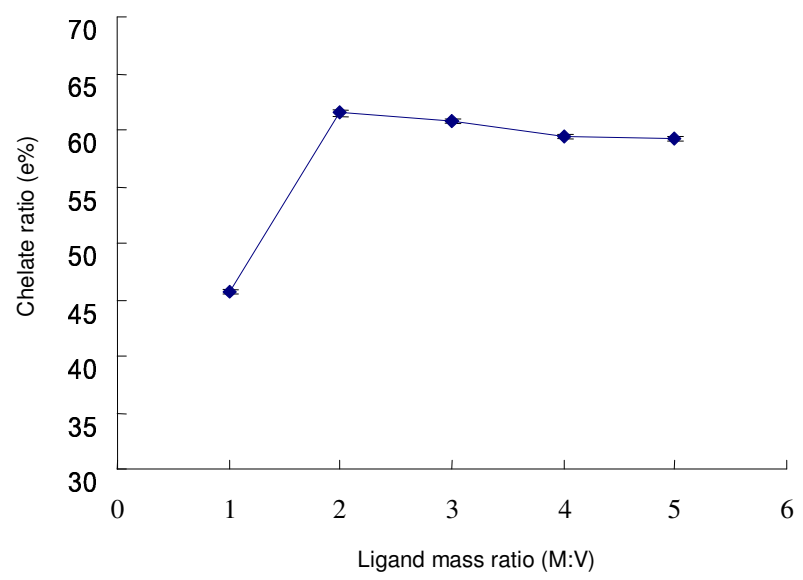

Figure 2. The effect of ligand mass ration on the chelate ration of chelate reaction.

\section{RESULTS AND DISCUSSION}

\section{Formation of soluble collagen peptide chelating calcium}

There are many factors that affects the synthesis and stability of the chelates, such as the $\mathrm{pH}$ (Hamodrakas et al., 2002), the proportion of peptides with calcium, the reaction temperature and reaction time. The coordination reaction of the general metal ions is a rapid reaction at room temperature, although the effects of temperature and time are not great. Appropriate heating in order to easily promote the reaction of ions was done only to improve the solubility of the peptide. Therefore, this test in reference to the relevant literature, fixed the reaction temperature at $50^{\circ} \mathrm{C}$ and at a reaction time of $30 \mathrm{~min}$. It mainly discussed the impact of the synthesis process from the reaction of the $\mathrm{pH}$ value and from the multipeptide and calcium mass ratio. The $\mathrm{pH}$ value in the experiment between 5 and 9 was selected to study the changes in the context of $\mathrm{pH}$ value on the chelating reaction (reaction coordinate 3:1) (Figure 1). As can be seen from Figure 1, with the increase of $\mathrm{pH}$, the chelating rate of collagen peptides and calcium rose and stabilized at the $\mathrm{pH}$ of 8 . This was due to the rise of the $\mathrm{pH}$ value and decrease in the concentration of $\mathrm{H}^{+}$, so that the coordination between $\mathrm{Ca}^{2+}$ with $\mathrm{NH}^{3+}$ and $\mathrm{COOH}^{-}$were enhanced (Kroll, 1984). When the $\mathrm{pH}$ value was greater than 8.0 , the rate of chelating decreased, which indicated that the hydroxide precipitate generation in the solution was not conducive to obtain pure polypeptide precipitated calcium chelating compounds, so the best response to the chelating compounds' $\mathrm{pH}$ value was 8.0 . The possible reason was that in its vicinity, there were many more acidic or alkaline substances in the skin close to the isoelectric point by hydrogen ions, where the light base was less provided adequately for the electron-donating groups, thus contributing to calcium through the coordination bond to form chelates.

Ligand mass ratio is the mass ratio of ligand and metal ion, which is an important factor for the chelating of metal ions and peptide (Jung et al., 2006a). If the coordination ratio is too small, chelate reaction is not significant to form a stable ring structure, and complexes will not be stable. If the coordination ratio is too high, it will result to a decline in peptide utilization, thereby resulting to waste and uneconomical peptides (Jung et al., 2006b). Therefore, different ligand mass ratio conditions were designed in the coordination reaction, and the results are shown in Figure 2. As it can be seen from the figure, when the mass ratio increased, the chelating rate increased; however, the rate of increase would be very different, in that if the ligand mass ratio is from $1: 1$ to $2: 1$, the rate of chelating increases so great, but when it is from $2: 1$ to $3: 1$, the rate of chelating increases very small. At last, the mass ratio of 2:1 was chosen.

\section{Molecular distribution of collagen protein hydrolyzates}

The distribution of calcium between the fractions of the different molecular weight in collagen protein hydrolyzates was determined by gel chromatography. Using a Sephadex G-25 column, collagen protein hydrolyzates were separated into 4 fractions with an average molecular weight of $81 \mathrm{kDa}$ for peak $1,3.9 \mathrm{kDa}$ for peak 2, $724 \mathrm{Da}$ for peak 3 and $117 \mathrm{Da}$ for peak 4 (Figure 3). As shown in Figure 3, the solid legends represent the absorbance of each fraction at $280 \mathrm{~nm}$, and the hollow legends represented the concentration of $\mathrm{Ca}^{2+}$ binding collagen protein hydrolyzates. From Figure 3 , it can be seen that the calcium was mainly associated with the $3.9 \mathrm{kDa}, 724 \mathrm{Da}$ and $117 \mathrm{Da}$ fractions. Previous study reported that the number of calcium binding sites in soybean globulin trypsin hydrolysates increased with increasing degree of hydrolysis, reaching a peak value When the degree of hydrolysis was $32 \%$ and then 


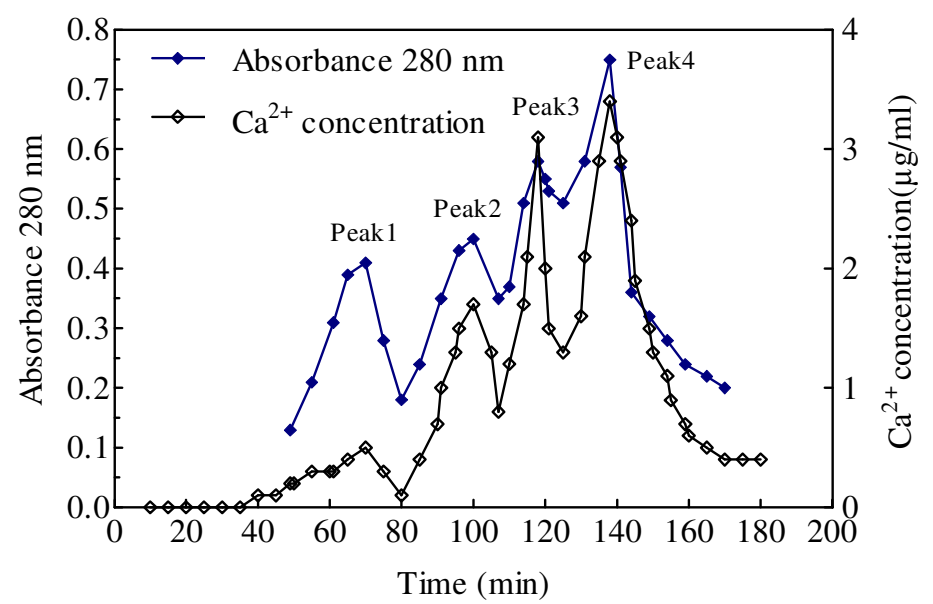

Figure 3. G-25 gel chromatography of collagen peptide hydrolyzate.

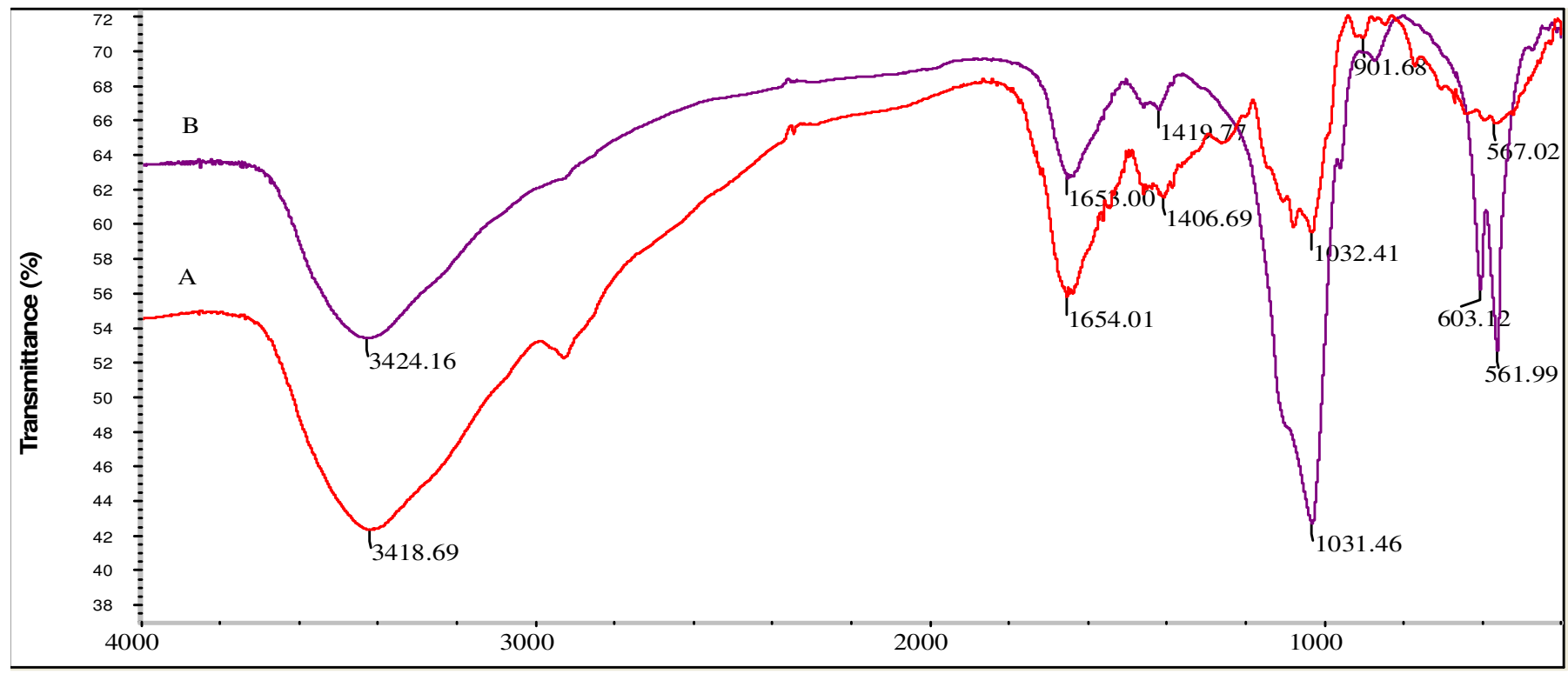

Wave number $\left(\mathrm{cm}^{-1}\right)$

Figure 4. Infrared spectral analysis of collagen peptide and collagen peptide chelating calcium.

decreased (Kumagai et al., 1998). Further hydrolysis resulted in a decrease in the number of binding sites and reduced the molecular weight, which led to a decrease in binding sites and a decrease in calcium binding capability. The gel chromatography results suggest that collagen protein hydrolyzate fragments with the highest calcium binding capacity had average molecular weights under $5 \mathrm{kDa}$.

\section{Infrared spectral analysis of collagen peptide chelating calcium}

Changes in the characteristic FTIR absorption peaks of carboxylates and amides in proteins can reflect the interaction of metal ions with the organic ligand groups in the protein (Mizuguchi et al., 2001). Figure 4 depicts the infrared spectrum of collagen peptide hydrolysates in the absence of calcium (A), after the addition of calcium (B) and lists the changes to peaks in the infrared absorption spectrum. After addition of calcium, the wave number $\left(3418 \mathrm{~cm}^{-1}\right)$ of the $-\mathrm{NH}_{2}$ was shifted to a higher frequency $\left(3425 \mathrm{~cm}^{-1}\right)$, while the wave number $(1654 \mathrm{~cm}$ $\left.{ }^{1}\right)$ of the $\mathrm{C}=\mathrm{O}$ was shifted to a lower frequency $\left(1653 \mathrm{~cm}^{-}\right.$ $\left.{ }^{1}\right)$, and the wave number $\left(1406 \mathrm{~cm}^{-1}\right)$ of the $-\mathrm{COO}-$ was shifted to a higher frequency $\left(1419 \mathrm{~cm}^{-1}\right)$. The results suggest that the interaction between collagen peptide 


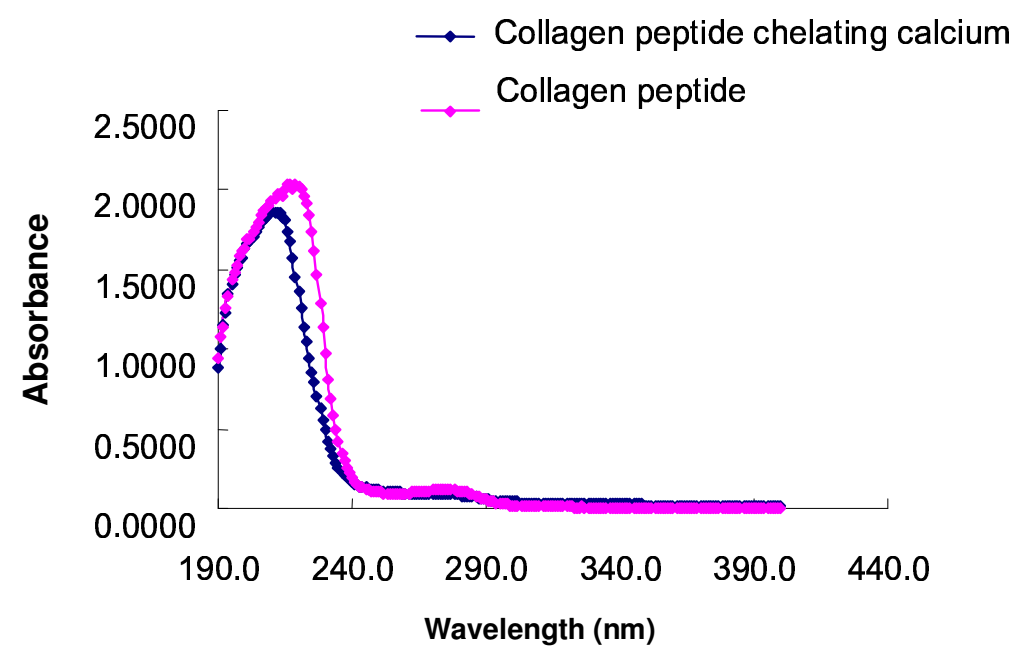

Figure 5. UV Scanning analysis of collagen peptide and collagen peptide chelating calcium.

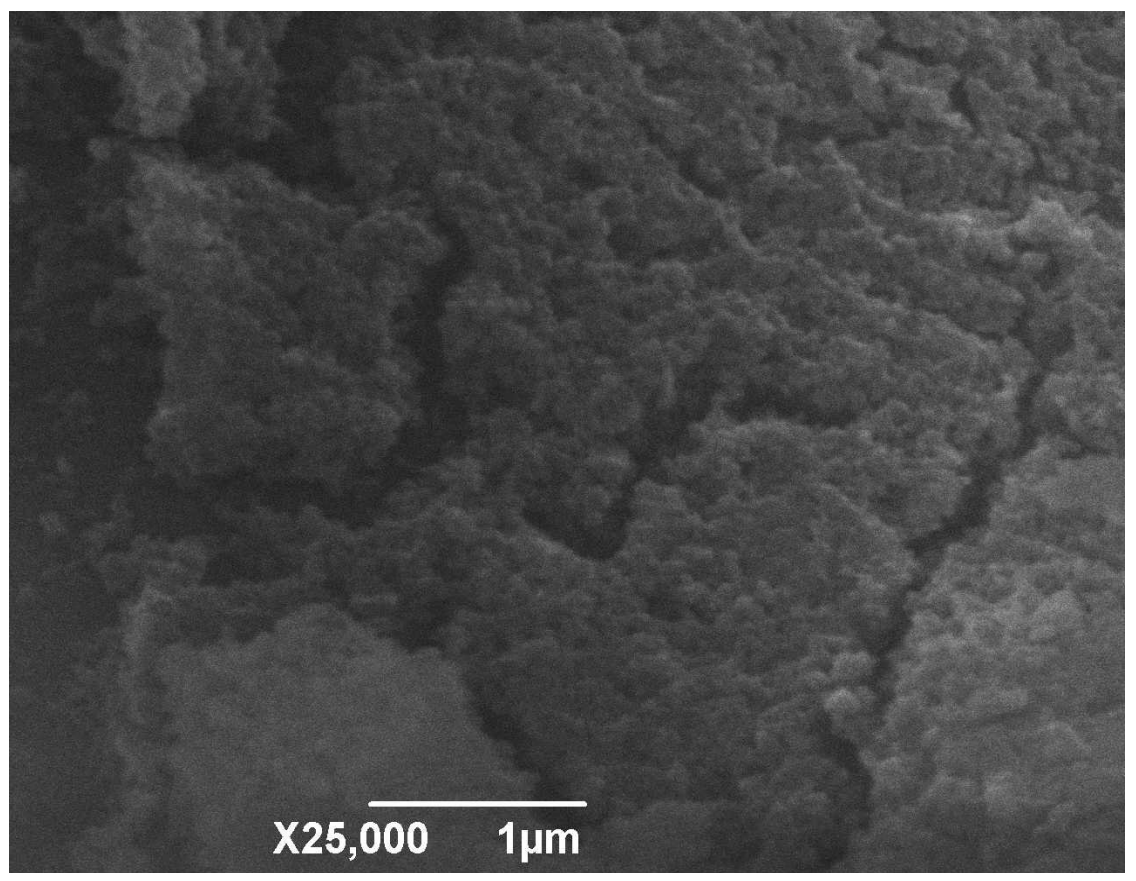

Figure 6. Scanning electron microscope of collagen peptide.

hydrolysates and calcium occurs via the carboxy oxygen atoms and amino nitrogen atom in the peptide (Gallagher et al., 2001).

\section{UV scanning analysis}

From Figure 5, it can be seen that the maximum absorption of collagen peptide peak is at $218 \mathrm{~nm}$, which is the characteristic absorption peak of the collagen peptide's bond carbonyl, while binding of the calcium beyond the maximum absorption peak moved to $208 \mathrm{~nm}$, with a significant left shift of $10 \mathrm{~nm}$. After collagen peptide binding with the calcium, different transitions reflected the corresponding atom's valence electrons, which could prove that collagen peptide had reacted with calcium.

\section{Scanning electron microscope}

Figures 6 and 7 show a group of electron microscope photos of collagen peptide before and after binding of 


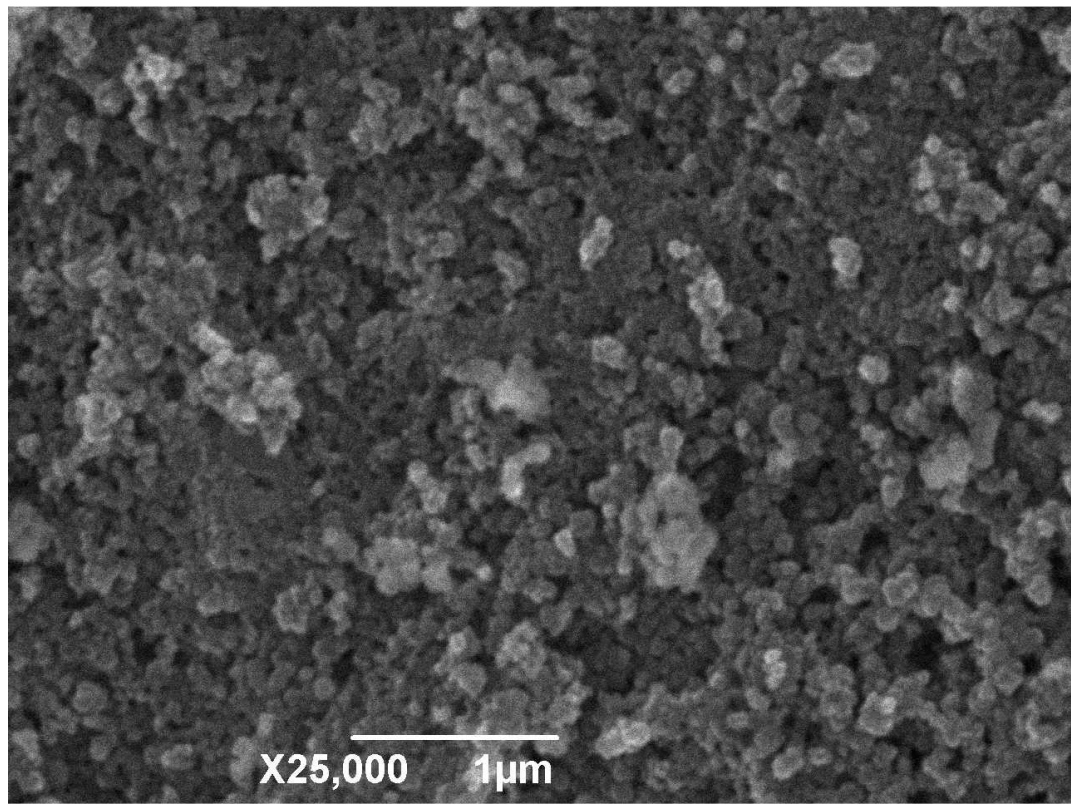

Figure 7. Scanning electron microscope of collagen peptide chelating calcium.

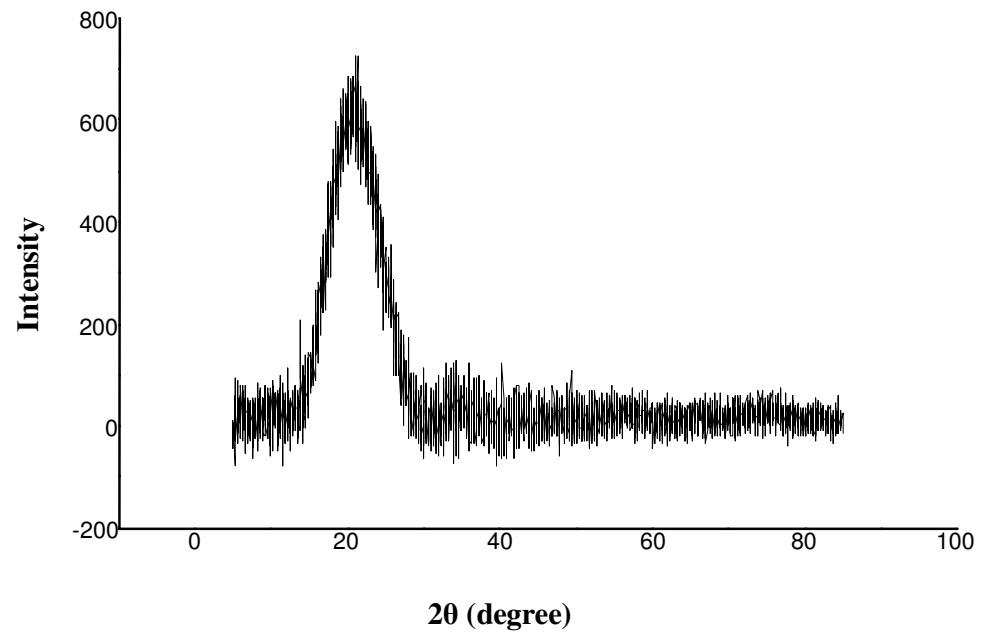

Figure 8. X-diffraction of collagen peptide.

calcium. Figure 6 shows collagen peptides in multiples of 25,000 under the electron microscope photographs, and it can be seen from the graph that a uniform distribution of the "groove", may be the hydrophilic areas of collagen peptides by the traces left by freeze-drying. Figure 7 shows collagen peptide and calcium chelating after multiples of 25,000 under the electron microscope photographs. From the graph, a lot of white grains "embedded" in the surface of collagen peptide can be clearly seen, and it may be adsorbed on the collagen peptide crystals of the aforementioned calcium. Thus, it was concluded that collagen peptides and calcium occurred in the chelating reaction. Apart from the chelating ligand binding and ion binding, there were also some certain adsorption.

\section{X-diffraction analysis}

Figure 8 shows the collagen peptide's X-diffraction spectras, while Figure 9 shows the collagen peptide chelating calcium's diffraction spectras. From the two spectras, it can be seen clearly that after collagen peptide was chelated with calcium, X-diffraction patterns changed materially. The amino acid composition of collagen peptides was not orderly arranged, therefore collagen peptide was amorphous and its spectra had no absorption peak. However, after chelation with calcium, it 


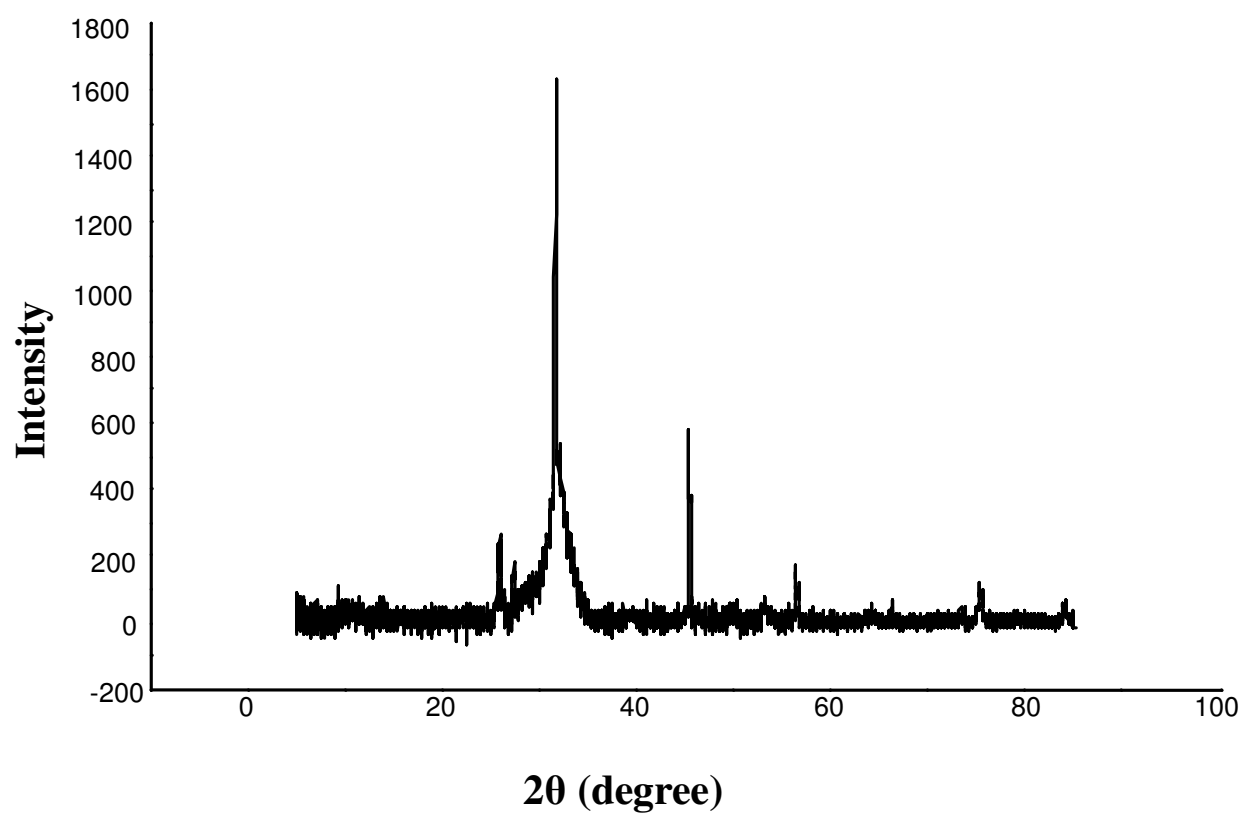

Figure 9. X-diffraction of collagen peptide chelating calcium.

was clearly seen that X-diffraction spectra had a strong absorption peak. The chelating approach with calcium has certain rules used to obtain the collagen peptide chelating calcium's X-ray diffraction spectra that have a small end, high and sharp diffraction peak, indicating that the crystal is good.

\section{Conclusion}

The results showed that a major part of collagen and calcium in the ox bone fraction could be recovered by a combination of gentle enzymic hydrolysis and chemical extraction. The results showed that, using G-25 gel chromatography, the collagen peptide hydrolysis is divided into four components. Each component of the calcium binding capacity was different and the components whose molecular weight was less than 5000 $\mathrm{Da}$ had a relatively high calcium binding capacity. In the infrared spectra experiment, after collagen peptides were combined with calcium, the amide I, II wave number was displaced, indicating that amino nitrogen atoms and oxygen atoms on the carboxyl group were involved in chelation. In the UV scan spectra, the characteristic absorption peak of the collagen peptide's carbonyl and the peptide bond is clearly shifted, indicating that the collagen peptides had a reaction with calcium. SEM spectra clearly showed a lot of white grains "embedded" in the surface of plastic peptide, indicating that there was a certain degree of adsorption, besides the reaction of coordination between collagen peptides and calcium. After it was combined with calcium, was clearly seen from the X-ray diffraction spectra that there were no rules of the non-crystal structure collagen peptides in the rules crystal structure.

\section{REFERENCES}

Anderson JJB, Garner SC (1996). Calcium and phosphorous nutrition in health and disease, Introduction. CRC Press, NewYork, USA.

Bao XL, Lv Y, Yang BC, Ren CG, Guo ST (2008). A study of the soluble complexes formed during calcium binding by soybean protein hydrolysates. J. Food Sci. 73: 117-121.

Bass JK, Chan GM (2006). Calcium nutrition and metabo-lism during infancy. Nutrition, 22: 1057-1066.

Gallagher SC, Gao ZH, Li S, Dyer RB, Trewhella J, Klee CB (2001). There is communication between all four $\mathrm{Ca}^{2+}$-bindings sites of calcineurin B. Biochemistry, 40: 12094-12102.

Hamodrakas SJ, Willis JH, Iconomidou VA (2002). A structural model of the chitin-binding domain of cuticle proteins. Insect Biochem. Mol. Biol. 32: 1577-1583.

Jung WK, Karawita R, Heo SJ, Lee BJ, Kim SK, Jeon YJ (2006a). Recovery of a novel Ca-binding peptidefrom Alaska Pollack (Theragra chalcogramma) back-bone by pepsinolytic hydrolysis. Process Biochem. 41: 2097-2100.

Jung WK, Kim SK (2007). Calcium-binding peptide derived from pepsinolytic hydrolysates of hoki (Johnius belengerii) frame. Eur. Food Res. Technol. 224: 763-767.

Jung WK, Lee BJ, Kim SK (2006b). Fish-bone peptideincreases calcium solubility and bio availability in ova-riectomised rats. Br. J. Nutr. 95: 124-128.

Kroll RD (1984). Effect of $\mathrm{pH}$ on the binding of Calcium ions by soybean proteins. Cereal Chem. 61: 490-495.

Kumagai H, Shizawa Y, Sakurai H, Kumagai H (1998). Influence of phytate removal and structure modification on calcium-binding properties of soybean globulins. Biosci. Biotechnol. Biochem. 62: 341-346.

Lee YS, Noguchi T, Naito H (1980). Phosphopeptides and soluble calcium in the small intestine of rats given a casein diet. Br. J. Nutr. 43: 457-467. 
Lonnerdal B, Sandberg AS, Sandstrom B, Kunz C (1989). Inhibitory effects of phytic acid and other inositolphos phateonzinc and calcium absorption in suckling rats. J. Nutr. 119: 211-214.

Miyazawa E, Yoshida T (1991). Effects of dietary levels of phytate and in organicphosphate on phytate break down and absorption of calcium and magnesium in rats. Nutr. Res. 11: 797-806.

Mizuguchi M, Fujisawa R, Nara M, Nitta K, Kawano K (2001). Fouriertransform infrared spectroscopic study of $\mathrm{Ca}^{2+}$-binding to osteocalcin. Calcif. Tissue Int. 69: 337-342.
Saito Y, Lee YS, Kimura S (1998). Minimum effective dose of casein phosphopeptides (CPP) for enhancement of calcium absorption in growing rats. Int. J. Vitam. Nutr. Res. 68: 335-340. 